PEMBELAJAR: Jurnal Ilmu Pendidikan, Keguruan, dan Pembelajaran

Volume 2 Nomor 2 Oktober 2018 Hal. 125-131

e-ISSN: 2549-9114 dan p-ISSN: 2549-9203

(Received: April-2018; Reviewed: Juni-2018; Published: Oktober 2018)

DOI: http://dx.doi.org/10.26858/pembelajar.v2i2.5726

\title{
Peseptual Motor Disabilitas Kecerdasan Pada Keterampilan Activity Of Daily Living
}

\author{
Noorita Dwi Sulistyaningrum ${ }^{a}$, Mumpuniarti $^{\mathrm{a}}$ \\ aPendidikan Luar Biasa, Fakultas Pascasarjana, Universitas Negeri Yogyakarta \\ Corresponding e-mail: nooritadwis@gmail.com
}

\begin{abstract}
Abstrak: Penelitian ini bertujuan untuk mengetahui dan mendeskripsikan kekuatan perseptual motor pada siswa dengan disabilitas kecerdasan dalam keterampilan activity of daily living (ADL). Metode penelitian yang digunakan adalah penelitian deskriptif dengan pendekatan kuantitatif. Data pada penelitian ini dikumpulkan melalui 3 (tiga) teknik pengumpulan data yaitu tes, observasi, dan wawancara. Partisipan pada penelitian ini terdiri dari 2 siswa disabilitas kecerdasan kelas II SDLB dengan rentang usia 8-12 tahun. Hasil yang diperoleh dari penelitian ini menunjukkan bahwa perseptual motor pada siswa disabilitas kecerdasan untuk keterampilan activity of daily living (ADL) masih belum lengkap, sehingga membutuhkan latihan untuk kemampuan perseptual motor. Hal tersebut dibuktikan dari hasil perseptual motor untuk keterampilan bina diri memakai pakaian berkancing sebesar 4,5 (perseptual motor belum lengkap), memakai kaos kaki sebesar 5 (perseptual motor lengkap) dan memakai sepatu sebesar 4 (perseptual motor belum lengkap). Berdasarkan hasil penelitian tersebut, nilai atau skor secara keseluruhan adalah 4,5 yang dikategorikan memiliki kemampuan perseptual motor belum lengkap, sehingga membutuhkan berbagai latihan agar memiliki kekuatan perseptual motor.
\end{abstract}

Kata kunci: Perseptual Motor, Activity of Daily Living (ADL), Siswa Disabilitas Kecerdasan

\begin{abstract}
This study aims to determine and describe the power of the perceptual motor in students with intellectual disabilities in skills activity of daily living (ADL). Research methods used is descriptive study with quantitative approach. The data in this study were collected through 3 (three) data collection techniques namely test, observation, and interview. Participants in this study consisted of 2 students with grade 2 SDLB intellectual disabilities with an age range of 8-12 years. The results obtained from this study indicate that perceptual motors in students with intellectual disabilities for activity of daily living (ADL) skills are still incomplete, requiring practice for ability perceptual motor. This is evidenced, from the results of perceptual motor for self-construction skills wearing buttoned clothes of 4.5 (perceptual motor is not yet complete), wearing socks of 5 (perceptual motor is complete) and wearing shoes of 4 (perceptual motor is not yet complete). Based on the results of the study, the overall score of 4.5 is categorized as having ability perceptual motor is not yet complete, thus requiring various exercises to have the power perceptual motor.
\end{abstract}

Keywords: Perceptual Motor, Activity of Daily Living (ADL), Student with Intellectual Disabilities dibawah licenci CC BY-NC-4.0 (https://creativecommons.org/licenses/by-nc/4.0/ ). 


\section{PENDAHULUAN}

Keterampilan activity of daily living (ADL) dibutuhkan oleh setiap individu terutama individu dengan disabilitas kecerdasan. Tujuannya memiliki keterampilan tersebut yaitu agar dapat melakukan kegiatan sehari-hari dengan baik dan benar. Sudarsini (2017: 37), mengungkapkan bahwa kegiatan ADL merupakan keterampilan yang harus diajarkan mengingat aktivitas tersebut merupakan keterampilan dasar manusia yang paling mendasar. Aktivitas dalam kehidupan seharihari (ADL) tersebut berkaitan dengan keterampilan hidup. Keterampilan hidup seharihari bagi disabilitas kecerdasan mendukung kemandirian di dalam kehidupan masa dewasa (Ayres, K. M., Mechling, L \& Sansosti, F.J.: 2013). Kemandirian dalam kehidupan seharihari bagi disabilitas kecerdasan merupakan kemampuan yang harus dilatihkan sejak kecil. Keterampilan hidup termasuk pembelajaran utama dan dibutuhkan bagi seorang disabilitas kecerdasan, karena dengan menguasai keterampilan hidup, seseorang tidak lagi bergantung kepada orangtua dalam memenuhi kebutuhan hidupnya dan dapat mewujudkan kehidupan sehari-hari yang produktif (Putri \& Murtiningsih, 2013: 157; Ayres, Mechling \& Sansosti, 2013: 260). Oleh karena itu, keterampilan ADL tersebut penting untuk dapat dikuasai oleh anak dengan disabilitas kecerdasan.

Keterampilan hidup mencakup semua aspek dalam kehidupan mulai dari kegiatan bangun tidur sampai tidur kembali. Misalnya, toilet, perawatan, dan perawatan pribadi lainnya hingga keterampilan mengelola uang, belanja bahan makanan, komunikasi dan keterampilan sosial. Wiggins (2007: 7) menyatakan bahwa ADL juga dapat termasuk perawatan diri, komunikasi, aktivitas fisik, fungsi sensorik, dan tidur. Anak dengan disabilitas kecerdasan pada keterampilan hidup yang dilatihkan dapat dari kegiatan bina diri atau bantu diri karena anak diharapkan dapat mengurus dirinya terlebih dahulu. Dengan demikian, anak dapat hidup mandiri dalam mengurus dirinya sendiri maupun dalam hidup bermasyarakat. Kemandirian dalam keterampilan hidup sehari-hari dapat dicapai oleh setiap individu termasuk anak disabilitas kecerdasan, apabila memiliki kemampuan perseptual motor.

Perseptual motor berkaitan dengan interpretasi informasi sensori yang berdampak pada aktivitas motorik atau gerakan. Proses persepsi motor tersebut melibatkan kemampuan lainnya seperti yang diungkapkan oleh Hyatt, Stephenson \& Carter (2009: 314), bahwa kemampuan persepsi motor memerlukan integrasi input sensoris (visual, auditori, dan kinestetik) dengan respon motorik halus atau kasar. Aktivitas motorik yang dihasilkan akan benar jika memiliki kemampuan motorik dan persepsi yang benar sehingga gerakan yang dihasilkan sesuai yang diharapkan. Sajedi \& Barati (2014: 14), mendukung bahwa salah satu faktor penting dalam perkembangan anak adalah kemampuan perseptual-motorik, yang meliputi (1) keterampilan motorik membutuhkan keterampilan perseptual, (2) menurut banyak penelitian, berfungsinya perseptual motor secara efektif sangat penting untuk memperbaiki peserta didik di ketiga bidang pendidikan dan pelatihan (kognitif, afektif dan psikomotor) dan juga untuk pengembangan keterampilan motorik. Tujuan dari pengembangan keterampilan perseptual motor yaitu agar anak mampu melakukan kegiatan sehari-hari yang menuntut keaktifan motorik kasar dan halus. Wuang, Wang, Huang \& Su, (2009: 442), menyatakan bahwa pendekatan perseptual motor mengasumsikan hubungan antara perilaku motorik dan proses perseptual yang mendasarinya. Perseptual motor tersebut menjadi bagian penting dalam aktivitas seharihari karena perseptual motor dibutuhkan dalam penguasaan semua kegiatan dalam kehidupan. Oleh karena itu, perkembangan perseptual motor perlu diperhatikan karena keterhambatan pada perkembangan motorik dan perseptual juga akan menyebabkan terjadinya kesulitan belajar akademik seperti yang terjadi pada anak disabilitas kecerdasan.

Persepsi pada disabilitas kecerdasan kurang berkembang sebagaimana mestinya sehingga mereka mengalami hambatan dalam menjalankan tugasnya. Ibrahim (2005: 41), menyatakan bahwa seseorang yang memiliki tingkat inteligensi yang rendah, bahkan dapat dikategorikan tunagrahita ringan cenderung memiliki persepsi yang tidak normal dan mempunyai masalah pada perseptual motorik. Perseptual motor melibatkan banyak kemampuan seperti kemampuan tangan, mata, dan otot-otot yang terlibat dalam gerak. Pada perkembangan motorik setiap anak melakukan gerak yang berhubungan dengan kerja otot-otot kecil maupun koordinasi tangan dan mata yang terlibat dalam kehidupan sehari-harinya 
(Badruzaman dan Saputra,Y, 2009:31). Anak disabilitas kecerdasan kemungkinan mengalami hambatan dalam penafsiran informasi yang diterima sehingga berdampak pada berbagai aspek termasuk pada kegiatan sehari-hari. Hasil penelitian Wuang, Wang, Huang \& Su, (2009: 441); Hyatt, Stephenson \& Carter, (2009: 314) menjelaskan bahwa disabilitas yang kesulitan dengan tugas motorik kasar dan halus akan menghalangi partisipasi dalam kegiatan sekolah, prestasi akademik, kemandirian dalam kehidupan sehari-hari, dan penerimaan sosial oleh teman sebaya. Fallen, Malpass, dan Umansky (2015:214); Carmeli, Yossef, Ariav, Levy \& Liebermann (2009: 323), hasil penelitiannya juga menunjukkan bahwa anak disabilitas kecerdasan mengalami kekurangan kompetensi motorik (ketidakmampuan untuk mengintegrasikan masukan visual dan gerakan tangan, koordinasi motor persepsi yang buruk) dalam tugas-tugas yang membutuhkan latihan gerakan tepat dan reaksi serta hal-hal yang membutuhkan keterampilan kompleks dan koordinasi motorik yang dapat menyebabkan pengecualian dari kegiatan kejuruan dan rekreasi, serta penurunan kompetensi ADL. Oleh karena itu, dapat diketahui bahwa gangguan atau hambatan yang terjadi pada persepsi, kemampuan motorik kasar dan halus dapat berdampak pada berbagai kegiatan dalam kehidupan sehari-hari. Hambatan atau kondisi pada anak dengan disabilitas kecerdasan tersebut dapat diatasi dengan berbagai latihan yang berhubungan dengan persepsi dan gerakan. Berdasarkan hal tersebut, maka penelitian ini akan menggambarkan tentang kekuatan perseptual motor pada aktivitas kehidupan sehari-hari pada anak disabilitas kecerdasan. Jadi penelitian ini bertujuan untuk mengetahui dan mendeskripsikan kekuatan perseptual motor pada siswa dengan disabilitas kecerdasan dalam keterampilan activity of daily living (ADL).

\section{METODE}

Penelitian ini menggunakan jenis penelitian deskriptif dengan pendekatan kuantitatif. Penelitian deskriptif merupakan penelitian yang berusaha mengungkap fakta suatu kejadian, objek, aktivitas, proses, dan manusia secara apa adanya pada waktu sekarang atau jangka waktu yang masih memungkinkan dalam ingatan responden (Prastowo, 2014: 203). Penelitian deskriptif ini akan membantu mengungkap kejadian yang sebenarnya. Selanjutnya, untuk pendekatan kuantitatif lebih menekankan fenomena-fenomena objektif dan dikaji secara kuantitatif yaitu menggunakan angka-angka, pengolahan statistik, struktur dan percobaan terkontrol (Hamdi \& Bahruddin, 2015: 5). Penelitian ini akan mengungkapkan tentang kekuatan perseptual motor pada siswa dengan disabilitas kecerdasan dalam keterampilan activity of daily living (ADL).

Penelitian ini dilakukan di Sekolah Luar Biasa (SLB) Negeri Pembina Yogyakarta. Penelitian ini melibatkan 2 siswa laki-laki dengan disabilitas kecerdasan dalam kategori sedang. Kedua siswa tersebut kelas II SDLB. Subjek dalam penelitian ini berada pada rentang usia 8-12 tahun. Subjek pada penelitian ini dipilih berdasarkan teknik purposive sampling. Subjek dipilih berdasarkan kriteria usia, karena pada usia 8-12 tahun persepsi dan motorik sudah berkembang.

Pengumpulan data dilakukan untuk memperoleh data mengenai kekuatan perseptual motor pada siswa disabilitas kecerdasan. Teknik pengumpulan data menggunakan teknik tes, observasi dan wawancara. Tes dilakukan dengan tes kinerja kemampuan perseptual motor siswa. Tes kemampuan perseptual motor ditinjau dari berbagai aktivitas yang berbeda sesuai dengan kebutuhan khusus setiap siswa. Tes kemampuan perseptual motor siswa disabilitas kecerdasan dalam aktivitas bina diri meliputi bina diri memakai kaos kaki, sepatu dan memakai pakaian. Tes dilakukan berdasarkan instrumen tes kinerja yang telah disusun. Tes terdiri dari tiga rentang skor 1-3, dengan skor 3 merupakan skor maksimal dan disertai kolom keterangan. Skor 1 diberikan jika siswa "belum memiliki persepsi", skor 2 diberikan jika siswa "memiliki persepsi yang belum lengkap" dan skor 3 diberikan jika siswa "memiliki persepsi yang lengkap". Data yang diperoleh dengan tes merupakan data utama, sedangkan data yang diperoleh dari observasi dan wawancara digunakan sebagai data pelengkap.

Observasi dilakukan dengan teknik observasi partisipan, sehingga peneliti terlibat langsung pada aktivitas yang dilakukan siswa agar aktivitas yang dimunculkan terjadi secara alami. Peneliti mencatat berbagai aktivitas yang berhubungan dengan kemampuan perseptual motor yang ditunjukkan siswa. Wawancara dilakukan pada orang tua dan guru. Wawancara dilakukan secara terstruktur, sehingga wawancara terarah sesuai dengan pedoman wawancara yang ada. Wawancara ini bertujuan untuk mengetahui kemampuan perseptual motor siswa disabilitas kecerdasan dalam aktivitas kehidupan sehari-hari di rumah dan di sekolah. 
Analisis data pada penelitian ini dilakukan dengan teknik analisis data deskriptif kuantitatif. Data dari hasil tes dianalisis secara deskriptif kuantitatif dengan persentase. Data hasil wawancara dan observasi dianalisis sebagai data pelengkap untuk menggambarkan mengenai kemampuan perseptual motor pada anak. Data yang telah dianalisis akan dimaknai dengan kategori untuk mengetahui pola kemampuan perseptual motor siswa disabilitas kecerdasan.

\section{HASIL DAN PEMBAHASAN}

\subsection{Hasil Penelitian}

Hasil dari analisis menghasilkan tentang deskripsi kekuatan persepsi motor pada siswa disabilitas kecerdasan dalam aktivitas kehidupan sehari-hari. Terdapat tiga aktivitas atau kegiatan bina diri yang diteliti untuk mengetahui kekuatan persepsi motor yaitu (1) perseptual motor pada kegiatan memakai pakaian, (2) perseptual motor pada kegiatan memakai kaos kaki, (3) perseptual motor pada kegiatan memakai sepatu. Hasil penelitian pada setiap kegiatan tersebut telah menunjukkan kemampuan atau kekuatan perseptual motor seperti memiliki perseptual motor yang lengkap, belum lengkap dan belum memiliki perseptul motor.

Perseptual motor pada keterampilan bina diri siswa disabilitas kecerdasan dilakukan terhadap dua siswa dan mencakup tiga kegiatan yaitu persepsi menggunakan pakaian, persepsi menggunakan kaos kaki serta persepsi menggunakan sepatu. Masing-masing kegiatan tersebut terdiri dari langkah-langkah kegiatan yang dinilai persepsinya untuk setiap langkahnya. Dari langkah-langkah yang diamati tersebut, kemudian hasilnya dijadikan satu sehingga diperoleh hasil akhir persepsi dari setiap kegiatan bina diri. Pada kegiatan memakai atau menggunakan pakaian berkancing terdapat dua puluh langkah kegiatan yang diamati, mulai dari mengambil pakaian berkancing sampai melipat kerah (lipat setengah dari tinggi kerah) ke arah luar dan lipat semua bagian kerah (bagian kanan, kiri dan belakang). Kegiatan memakai kaos kaki terdiri dari lima langkah kegiatan yaitu (1) mengambil kaos kaki, (2) menunjuk dan memegang kaos kaki untuk kaki sebelah kanan, (3) menunjuk dan memegang kaos kaki untuk kaki sebelah kiri, (4) memasukkan kaki kanan ke dalam kaos kaki yang kanan, (5) memasukkan kaki kiri ke dalam kaos kaki yang kiri. Pada kegiatan memakai sepatu juga terdiri dari tujuh langkah kegiatan yaitu (1) mengambil sepatu yang tidak bertali (rekatan), (2) menunjuk dan memegang sepatu yang dipakai kaki kanan, (3) menunjuk dan memegang sepatu yang dipakai kaki kiri, (4) membuka rekatan sepatu, (5) memasukkan kaki kanan ke dalam sepatu kanan, (6) memasukkan kaki kiri ke dalam sepatu kiri, dan (7) merekatkan sepatu. Beberapa langkah-langkah atau analisis tugas tersebut merupakan langkah kegiatan yang diamati agar mengetahui kekuatan perseptual motor pada setiap langkah kegiatan bina diri. Berikut ini hasil penelitian perseptual motor terhadap keterampilan bina diri yang digambarkan dalam diagram garis, yaitu:

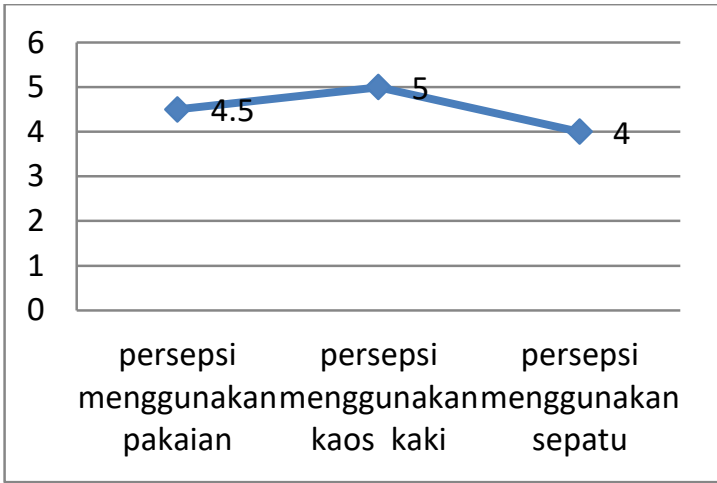

\section{Gambar 1. Diagram Garis Kekuatan Perseptual Motor Terhadap Keterampilan Bina Diri}

Berdasarkan grafik di atas dapat disimpulkan bahwa persepsi siswa disabilitas kecerdasan masih belum lengkap untuk beberapa kegiatan tetapi ada juga yang masuk dalam kategori lengkap. Hal ini dibuktikan dari hasil penelitian yang menunjukkan bahwa untuk persepsi menggunakan pakaian berkancing hasilnya 4,5 dan persepsi menggunakan sepatu hasilnya 4 . Rentang nilai tersebut masuk pada nilai 3-4 sehingga dapat dikategorikan belum memiliki persepsi yang lengkap. Sedangkan untuk persepsi menggunakan kaos kaki hasilnya 5 dan sudah masuk dalam kategori lengkap. Hal tersebut karena rentang nilai 5-6 masuk kategori memiliki persepsi yang lengkap. Berdasarkan ketiga hasil tersebut, dapat disimpulkan bahwa nilai secara keseluruhan yaitu sebesar 4,5 yang artinya kemampuan perseptual motor dalam keterampilan ADL belum lengkap atau masih kurang.

Hasil grafik menunjukkan bahwa kemampuan perseptual motor pada siswa dengan disabilitas kecerdasan masih kurang. 
Kurangnya kemampuan tersebut terlihat di beberapa langkah dalam kegiatan bina diri, seperti masih kurang paham dalam melakukan langkah kegiatan dan salah dalam menggerakkan tangan sehingga berdampak pada keberhasilan kegiatan bina diri yang dilakukan. Penyebab dari kurangnya kemampuan perseptual motor tersebut karena memang kondisi siswa disabilitas kecerdasan yang mengalami banyak permasalahan yang kompleks, seperti kemampuan motoriknya yang kurang, pusat perhatiannya yang mudah beralih serta masih kurang mampu dalam koordinasi tangan dan mata. Dengan demikian, keterampilan aktivitas hidup sehari-hari terkait bina diri pada siswa disabilitas kecerdasan perlu dikembangkan atau dikuatkan lagi dengan berbagai latihan perseptual motor sehingga dapat memiliki perseptual motor yang kuat.

\subsection{Pembahasan}

Perseptual motor diperlukan dalam aktivitas kehidupan sehari-hari sehingga kemampuan tersebut menjadi aspek yang penting untuk dapat dimiliki oleh individu. Begitu juga dengan siswa dengan disabilitas kecerdasan yang membutuhkan keterampilan persepsi motor agar dapat melakukan kegiatan sehari-hari dengan baik. Seseorang yang memiliki tingkat inteligensi yang rendah, cenderung memiliki persepsi yang tidak normal dan mempunyai masalah pada perceptual motorik (Ibrahim, 2005: 41). Tahapan perkembangan motorik halus setiap anak memang berbeda satu sama lainnya, perkembangan ini didasarkan pada kemampuan intelektual anak secara individu. Wuang, Wang, Huang \& Su, (2009: 442), juga menyatakan bahwa pendekatan perseptual motor mengasumsikan hubungan antara perilaku motorik dan proses perseptual yang mendasarinya. Perkembangan motorik merupakan salah satu aspek yang penting dalam kehidupan anak, karena pada dasarnya setiap anak melakukan gerak yang berhubungan dengan kerja otot-otot kecil maupun koordinasi tangan dan mata yang terlibat dalam kehidupan sehari-harinya (Badruzaman dan Saputra, $Y$, 2009:31). Hasil penelitian Fallen, Malpass, dan Umansky (2015:214) menunjukkan bahwa sebagai anak disabilitas kecerdasan menunjukkan kekurangan kompetensi motorik dalam tugas-tugas yang membutuhkan latihan gerakan tepat dan reaksi serta hal-hal yang membutuhkan keterampilan kompleks dan koordinasi motorik.
Keterampilan aktivitas kehidupan seharihari (ADL) bagi siswa disabilitas kecerdasan masih memiliki kemampuan perseptual motor yang kurang sehingga dalam melakukan keterampilan ADL masih belum benar. Hal tersebut dapat dikarenakan kemampuan perseptual motor melibatkan banyak kemampuan. Proses persepsi motor tersebut melibatkan kemampuan lainnya seperti yang diungkapkan oleh Hyatt, Stephenson \& Carter (2009: 314), bahwa kemampuan persepsi motor memerlukan integrasi input sensoris (visual, auditori, dan kinestetik) dengan respon motorik halus atau kasar. Perseptual motor tersebut menjadi bagian penting dalam keterampilan bina diri karena pada kegiatan tersebut perseptual motor menjadi salah satu bagian yang utama. Berdasarkan hasil penelitian Carmeli, Yossef, Ariav, Levy \& Liebermann (2009: 323), bahwa disabilitas intelektual berkaitan dengan ketidakmampuan untuk mengintegrasikan masukan visual dan gerakan tangan, koordinasi persepsi motor yang buruk dapat menyebabkan pengecualian dari kegiatan kejuruan dan rekreasi, dan penurunan kompetensi ADL. Oleh karena itu, adanya hambatan perseptual motor pada siswa disabilitas kecerdasan berpengaruh besar pada kegiatan binadiri yang dilakukan siswa.

Berdasarkan hasil penelitian, dapat diketahui bahwa siswa dengan disabilitas kecerdasan belum memiliki perseptual motor yang lengkap dalam aktivitas kehidupan seharihari, sehingga membutuhkan latihan. Wiggins (2007: 7) menyatakan bahwa ADL dapat termasuk perawatan diri, komunikasi, aktivitas fisik, fungsi sensorik, dan tidur. Aktivitas hidup sehari-hari (ADL) yang diteliti yaitu terkait kegiatan bina diri memakai pakaian berkancing, memakai kaos kaki dan memakai sepatu. Ketiga kegiatan tersebut membutuhkan kemampuan atau kekuatan perseptual motor agar dapat dilakukan dengan benar. Meskipun, yang dijadikan penelitian hanya tiga kegiatan, tetapi secara keseluruhan sudah dapat menggambarkan kemampuan perseptual motor yang dimiliki siswa disabilitas kecerdasan yaitu masih belum lengkap atau masih kurang kemampuan perseptual motornya. Padahal kemampuan tersebut sangat penting dan diperlukan untuk setiap kegiatan ADL. Keterampilan hidup sehari-hari bagi disabilitas kecerdasan mendukung kemandirian di dalam kehidupan masa dewasa (Ayres, K. M., Mechling, L \& Sansosti, F.J.: 2013). Kegiatan ADL juga 
merupakan keterampilan dasar manusia yang paling mendasar (Sudarsini, 2017: 37). Oleh karena itu, kemampuan atau kekuatan perseptual motor sangat penting untuk dimiliki anak dengan disabilitas tersebut agar dapat melakukan aktivitas kehidupan secara mandiri. Sajedi \& Barati (2014: 14), juga mendukung bahwa salah satu faktor penting dalam perkembangan anak adalah kemampuan perseptual-motorik, yang meliputi (1) keterampilan motorik membutuhkan keterampilan perseptual, (2) perseptual motor sangat penting untuk memperbaiki peserta didik di ketiga bidang pendidikan dan pelatihan (kognitif, afektif dan psikomotor) dan untuk pengembangan keterampilan motorik.

Siswa dengan disabilitas intelektual memiliki kekuatan perseptual motor yang rendah sehingga berdampak pada aktivitas kehidupannya. Wuang, Wang, Huang \& Su, (2009: 441); Hyatt, Stephenson \& Carter, (2009: 314) menjelaskan bahwa disabilitas yang kesulitan dengan tugas motorik kasar dan halus akan menghalangi partisipasi dalam kegiatan sekolah, prestasi akademik, kemandirian dalam kehidupan sehari-hari, dan penerimaan sosial oleh teman sebaya. Oleh karena itu, pembelajaran bagi siswa dengan disabilitas kecerdasan difokuskan untuk keterampilan aktivitas kehidupannya. Keterampilan akivitas hidup sehari-hari termasuk pembelajaran utama dan dibutuhkan bagi seorang disabilitas kecerdasan, karena dengan menguasai keterampilan tersebut, seseorang tidak lagi bergantung kepada orangtua dalam memenuhi kebutuhan hidupnya dan dapat mewujudkan kehidupan sehari-hari yang produktif (Putri \& Murtiningsih, 2013: 157; Ayres, Mechling \& Sansosti, 2013: 260). Dengan demikian, disabilitas kecerdasan sangat perlu diberikan latihan untuk perseptual motornya sehingga dapat melakukan keterampilan aktivitas hidup sehari-hari (ADL) dengan baik.

\section{KESIMPULAN DAN SARAN}

Berdasarkan hasil penyajian data dan pembahasan dapat disimpulkan bahwa kemampuan perseptual motor dalam kegiatan bina diri pada anak disabilitas intelektual masih memiliki kemampuan yang belum lengkap atau masih kurang. Kemampuan perseptual motor yang masih kurang yaitu pada kegiatan bina diri memakai pakaian berkancing dan memakai sepatu. Sedangkan, untuk kegiatan bina diri memakai kaos kaki, sudah memiliki kemampuan perseptual motor yang lengkap. Berdasarkan hasil penelitian, nilai atau skor secara keseluruhan adalah 4,5 yang dikategorikan memiliki kemampuan perseptual motor belum lengkap Oleh karena itu, kemampuan anak terkait perseptual motor untuk keterampilan aktivitas hidup sehari-hari harus selalu dilatihkan agar memiliki kekuatan perseptual motor yang diharapkan. Peningkatan kemampuan perseptual motor dapat dilakukan dengan berbagai aktivitas yang dapat mendorong anak untuk berlatih mengoptimalkan kemampuan perseptual motor. Dari hasil penelitian, dapat diketahui bahwa anak disabilitas kecerdasan masih belum memiliki persepsi yang lengkap dalam aktivitas kehidupan sehari-hari (ADL), sehingga membutuhkan penguatan dengan berbagai latihan melalui aktivitas fisik.

Saran dari penelitian ini adalah: (a) Bagi guru, agar dapat memberikan program pembelajaran yang dapat mengetahui dan melatih kemampuan perseptual motor siswa dengan disabilitas kecerdasan; (b) Bagi sekolah, agar dapat menyusun program pendidikan bagi siswa dengan disabilitas kecerdasan yang dapat meningkatkan kemampuan perseptual motor dalam melakukan activity of daily living (ADL); (c) Bagi orangtua, agar dapat memberikan latihan-latihan perseptual motor pada siswa disabilitas kecerdasan di rumah sehingga pembelajaran di sekolah dan di rumah saling berkesinambungan; (d) Bagi peneliti, agar dapat melakukan penelitian lebih mendalam tentang kemampuan perseptual motor untuk berbagai activity of daily living (ADL) sehingga dapat diketahui kemampuan siswa disabilitas kecerdasan untuk setiap ADL.

\section{UCAPAN TERIMA KASIH}

Penulis mengucapkan terimakasi kepada SLB Negeri Pembina Yogyakarta atas izin yang diberikan untuk melakukan penelitian dan semua pihak yang telah memberikan dukungan serta saran dalam penelitian ini.

\section{DAFTAR PUSTAKA}

Ayres, K. M., Mechling, L \& Sansosti, F.J. (2013). The Use Of Mobile Technologies To Assist With Life Skills/Independence Of Students With Moderate/SevereIntellectual Disability And/Or Autism Spectrum Disorders: Considerations ForThe Future Of School 
Psychology. Jurnal Psikologi, Vol. 50(3), Diakses dariwileyonlinelibrary.com/journal/pits.

Badruzaman \& Saputra,Y. (2009). Perkembangan dan Belajar Motorik. UPI Bandung.

Carmeli, E., Yossef,T.B., Ariav,C., Levy,R., \& Liebermann, D.G. (2009). Perceptualmotor Coordination in Persons with Mild Intellectual Disability.Journal Disability and Rehabilitation, Vol. 30, Issue 5.

Fallen, Malpass \& Umansky (2015). Psychomotor therapy targeting anger and aggressive behaviour in individuals with mild or borderline intellectual disabilities: A systematic review. Journal of Intellectual \& Developmental Disability , Vol 25, Issue 3

Hamdi, A.S. \& Bahruddin, E. (2015). Metode Penelitian Kuantitatif Aplikasi dalam Pendidikan. Yogyakarta: Deepublish.

Hyatt, K.J, Stephenson, J \& Carter, M. (2009). A Review of Three Controversial Educational Practices: Perceptual Motor Programs, Sensory Integration, and Tinted Lenses. Jurnal Education and Treatment of Children. Vol. 32, No. 2. Western Washington University, Bellingham, Macquarie University, Sydney Australia.

Ibrahim, R. (2005). Psikologi pendidikan jasmani olahraga PLB. Jakarta: Depdiknas

Prastowo, A.(2014). Memahami Metodemetode Penelitian: Suatu Tinjauan Teoretis dan Praksis. Yogyakarta: Ar-Ruzz Media.

Putri, P dan Murtiningsih, A. (2013). Kiat Sukses. Mengasuh Anak Berkebutuhan Khusus. Yogyakarta: Ar - Ruzz Media.

Sajedi, F \& Barati, H. (2014). The effect of Perceptual Motor Training on Motor Skills of preschool children. Iranian Rehabilitation Journal, Vol. 12, No. 19. University of Social Welfare and Rehabilitation Sciences, \& University of Allameh Tabatabayi. Tehran, Iran.
Sudarsini. (2017). Fisioterapi. Malang: Gunung Samudera.

Wiggins, C.E. (2007). A Concise Guide to Orthopaedic and Musculoskeletal Impairment Ratings. USA: Lippincott Williams \& Wilkins.

Wuang, Y.P., Wang, C.C., Huang, M.H., \& Su, C.Y. (2009). Prospective Study of the Effect of Sensory Integration, Neurodevelopmental Treatment, and Perceptual-Motor Therapy on the Sensorimotor Performance in Children With Mild Mental Retardation. The American Journal of Occupational Therapy American Journal of Occupational Therapy, 63, 441. https://doi.org/10.5014/ajot.63.4.441 